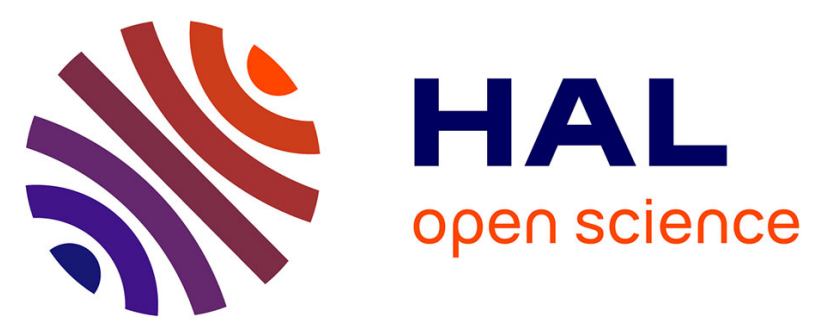

\title{
Thin film dissolution into semi-infinite substrates: surprising interface kinetics and dissolution modes
}

Z Erdélyi, Ch Girardeaux, D L Beke, J. Bernardini, A. Portavoce, G L Katona, Z Balogh, A Rolland

\section{- To cite this version:}

Z Erdélyi, Ch Girardeaux, D L Beke, J. Bernardini, A. Portavoce, et al.. Thin film dissolution into semi-infinite substrates: surprising interface kinetics and dissolution modes. Defect and Diffusion Forum, 2009, 289-292, pp.573-585. hal-02406639

\section{HAL Id: hal-02406639 \\ https://hal-amu.archives-ouvertes.fr/hal-02406639}

Submitted on 12 Dec 2019

HAL is a multi-disciplinary open access archive for the deposit and dissemination of scientific research documents, whether they are published or not. The documents may come from teaching and research institutions in France or abroad, or from public or private research centers.
L'archive ouverte pluridisciplinaire $\mathbf{H A L}$, est destinée au dépôt et à la diffusion de documents scientifiques de niveau recherche, publiés ou non, émanant des établissements d'enseignement et de recherche français ou étrangers, des laboratoires publics ou privés. 


\title{
Thin film dissolution into semi-infinite substrates: surprising interface kinetics and dissolution modes
}

\author{
Z. Erdélyi ${ }^{1, a}$, Ch. Girardeaux ${ }^{2}$, D.L. Beke ${ }^{1}$, J. Bernardini ${ }^{2}$, A. Portavoce ${ }^{2}$, G.L. \\ Katona ${ }^{1}$, Z. Balogh ${ }^{1}$, A. Rolland ${ }^{2}$ \\ ${ }^{1}$ Department of Solid State Physics, University of Debrecen, P.O. Box.2, H-4010 Debrecen, \\ Hungary
}
${ }^{2}$ Aix-Marseille Université, FST Campus de Saint-Jérôme, Avenue Escadrille Normandie Niemen - Case 142, F-13397 Marseille Cedex, France
${ }^{3}$ CNRS, IM2NP (UMR 6242) FST Campus de Saint-Jérôme, Avenue Escadrille Normandie Niemen - Case 142, F-13397 Marseille Cedex, France

azerdelyi@dragon.unideb.hu

\begin{abstract}
Keywords: thin film dissolution, anomalous diffusion kinetics, solid state reaction, AES, XPS, $\mathrm{XRD}$, computer simulations and experiments

Abstract. Depending on the thermodynamic, structural and diffusion properties of the system, a thin deposit dissolves into a substrate by different mechanisms. In this communication these different behaviours, investigated by surface analytical techniques (AES, XPS, STM, UPS, etc) [17], are reviewed. The experiments were also supported by computer simulations. The obtained results are compared and it is summarized how different parameters influence the dissolution of a thin film in a substrate. Furthermore, it is show that i) the volume dissolution kinetics is different on the atomic-/nano-scale than on the microscopic scale due to the diffusion asymmetry ii) the volume and GB diffusion in one measurement can be separated and iii) pure (C-kinetic) GB diffusivities can be determined from thin film kinetics measurements performed under adequate conditions.
\end{abstract}

\section{Introduction}

In the last years systematic studies of dissolution of thin (1-3 nm) deposits into semi-infinite substrates have been performed in our laboratories. It was investigated how different parameters influence the dissolution process of the thin film into the substrate. These parameters are related to the following properties of the system:

i) thermodynamic: completely miscible or phase separating system, segregation tendency;

ii) structural: crystalline or amorphous structures;

iii) diffusion: volume or grain-boundary diffusion.

From diffusion point of view, the less complex situation is when the deposit is grown epitaxially onto a single crystalline substrate or if both the deposit and the substrate are amorphous, since in theses cases only volume diffusion is expected to play a role in the dissolution process. Even in this 'simplest' situation theoretically more sub-cases can be envisaged: the diffusivity can be equal or different in the deposit and in the substrate. In nature, the diffusivities are practically never identical in different pure materials. The difference is typically several orders of magnitude. This is called diffusion asymmetry. In our experimental setup the diffusion was always slower in the deposits. Note that in this case the substrate atoms had segregation tendency. If one or both of the deposit and the substrate are polycrystalline, grain-boundary (GB) diffusion also becomes important. Regarding the thermodynamics, the deposit-substrate binary system can be completely miscible or phase separating in all the above cases.

In this contribution a systematic review of six systems is given, which cover the most important practical cases. The properties of the studied systems are summarized in Table 1. 
Table 1. List of the studied systems. (*not measured by surface analytical technique)

\begin{tabular}{|c|c|c|c|}
\hline \multicolumn{4}{|c|}{ LIST OF THE STUDIED SYSTEMS } \\
\hline $\begin{array}{c}\text { system } \\
\text { film/substrate }\end{array}$ & $\begin{array}{c}\text { thermodynamic } \\
\text { properties }\end{array}$ & $\begin{array}{c}\text { structure } \\
\text { film/substrate }\end{array}$ & diffusion type \\
\hline $\mathrm{Ni} / \mathrm{Cu}$ & ideal & $\begin{array}{c}\text { crystalline } \\
\text { epitaxial/single }\end{array}$ & volume \\
\hline \multirow{2}{*}{$\mathrm{Si} / \mathbf{G e}$} & \multirow{2}{*}{ ideal } & $\begin{array}{c}\text { amorphous } \\
\text { amorphous/amorphous }\end{array}$ & \multirow{2}{*}{ volume } \\
\hline & & $\begin{array}{c}\text { crystalline } \\
\text { quasi epitaxial/single }\end{array}$ & \\
\hline $\mathrm{Ni} / \mathrm{Au}$ & phase separating & $\begin{array}{l}\text { crystalline } \\
\text { textured poly/single }\end{array}$ & $\begin{array}{l}\text { volume, } \\
\text { grain-boundary }\end{array}$ \\
\hline $\mathrm{Cu} / \mathrm{Ag}$ & phase separating & $\begin{array}{l}\text { crystalline } \\
\text { poly/poly }\end{array}$ & grain-boundary \\
\hline $\mathbf{P d} / \mathbf{A g}$ & ideal & $\begin{array}{l}\text { crystalline } \\
\text { poly/single }\end{array}$ & grain-boundary \\
\hline $\mathrm{Co} / \mathrm{Si}$ * & ordering & poly/amorphous & solid state reaction \\
\hline
\end{tabular}

Finally, a recent result, which was not measured by surface analytical techniques but thematically fits to the main findings of the previous studies, is also presented. Diffusion kinetics in this $\mathrm{Co} / \mathrm{Si}$ system was followed by synchrotron x-ray diffraction (XRD) and four-wire resistance (4WR) techniques.

\section{Models}

When a system with thin film deposited onto a thick substrate is annealed, basically two types of situations have been investigated in the literature. One is when the film is polycrystalline and the substrate structure may be arbitrary, and the sample is heat-treated at low temperatures. Under these conditions the grain-boundary diffusion in the deposit plays practically the only role (Harrison Cregime). The other situation is when the thin film is epitaxialy grown onto the surface of a single crystalline substrate. In this case the only diffusion mechanism which can operate is the volume diffusion.

Grain-boundary diffusion in the Hwang-Balluffi model. Hwang et al. [8] analysed the problem of diffusion in an array of uniformly spaced parallel grain boundaries in a thin-film system under the conditions of $\mathrm{C}$ kinetics. In this regime, volume diffusion is essentially frozen out so that the material transport takes place only within the grain boundaries without any leakage into the adjoining grains. The geometry and the notations of the thin-film system analyzed are illustrated in Fig. 1.

Hwang and Balluffi developed a mathematical analysis to interpret accumulation kinetics measurements. They assumed that the atoms arriving from the grain boundaries spread out on the surface.

They determined a relation, which links the grain-boundary diffusion coefficient $D_{b}$ with the average concentration $c_{s}$ of the accumulation surface. This Hwang-Balluffi relation is given by:

$$
\begin{aligned}
& \left(k^{\prime \prime} / k^{\prime}\right) c_{s} / c_{0}=1-\exp \left(-\omega t^{\prime}\right), \\
& \omega=\delta D_{b} \lambda / \delta_{s} h k^{\prime} .
\end{aligned}
$$


Here $\lambda$ is the grain-boundary density (e.g. for a polycrystal having cubic grains with a lateral size $d$, $\lambda=2 / d) . k^{\prime}$ is the segregation coefficient at the accumulation surface/grain-boundary interface and $k$ ' the segregation coefficient at the grain-boundary/source interface. They are defined by the proportions $c_{s} / c_{b}$ and $c_{b} / c_{0}$, respectively. The form given here is not exactly that written in [8], and this is a more general version of it $[9,10]$. The $t$ ' quantity is a "corrected time" of the form $t^{\prime}=t-t_{0}$, where $t_{0}$ is a constant, taking into account that a transient phenomenon occurs in each diffusion measurement before a quasi-steady-state is reached and $t$ is the real time.

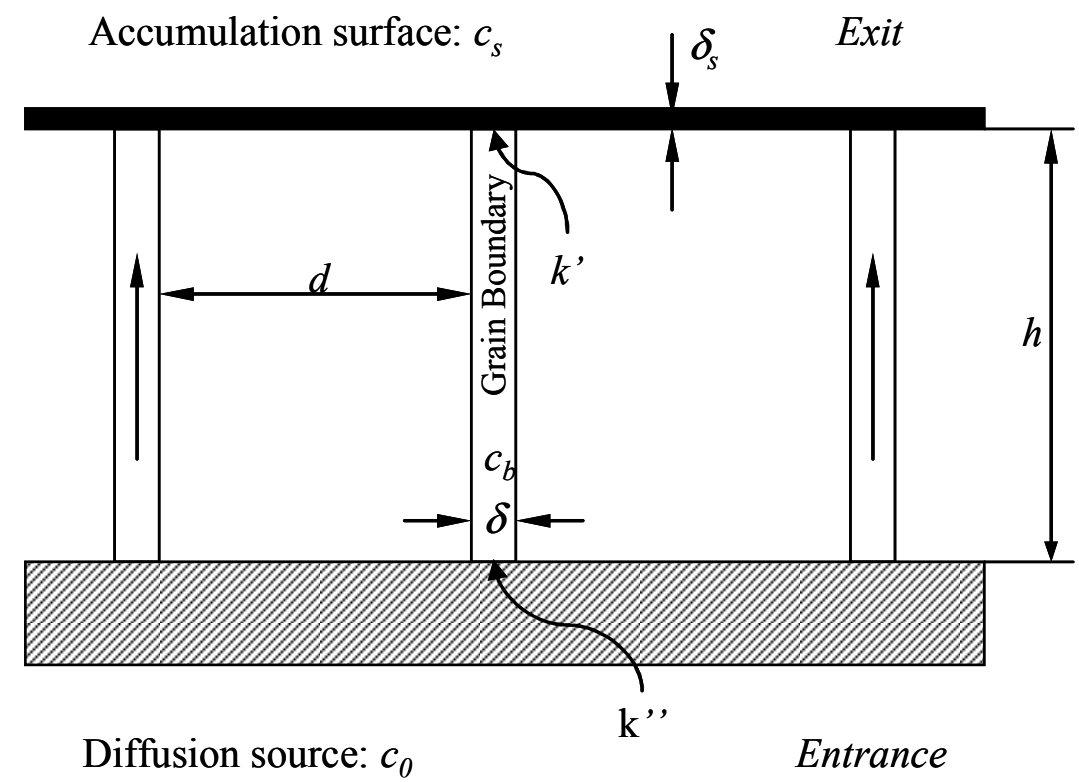

Fig. 1, Geometry of the thin film system used in the Hwang-Balluffi method

As $k$ "'/k' ratio is usually not known, in practice it is useful to rewrite Eq. 1 in the following form:

$$
c_{s} / c_{0}^{\prime}=1-\exp \left(-\omega t^{\prime}\right)
$$

where $c_{0}^{\prime}=c_{0} k^{\prime} / k^{\prime \prime}$. Then rearranging the equation and taking the natural logarithm of both sides, one obtains:

$$
\ln \left(1-c_{s} / c_{0}^{\prime}\right)=-\omega t^{\prime} .
$$

This means that if $c_{0}^{\prime}$ was known, plotting the natural logarithm of $\left(1-c_{s} / c_{0}^{\prime}\right)$ as a function of $t^{\prime}, \omega$ would be equal to the slope of the fitted line. $c_{0}^{\prime}$ can be determined by trial and error: we change the value of $c_{0}^{\prime}$ until the confidence of the regression is the best. When $c_{0}^{\prime}$ has been determined, one simply reads the slope of the corresponding fitted line, which is just the value of $\omega$.

Volume diffusion in kinetic mean field model. The model mainly used in our calculations is based on Martin's deterministic kinetic equations [11], in which the time derivatives of atomic fractions of $\mathrm{A}$ atoms in the $i$-th atomic layer perpendicular to the $\mathrm{x}$-axis can be given by:

$$
d c_{i} / d t=J_{i-1, i}-J_{i, i+1} .
$$

Here $J_{i, i+1}$ is the net flux of A atoms from plane $i$ to $(i+1)$ per lattice site:

$$
J_{i, i+1}=z_{v}\left[c_{i}\left(1-c_{i+1}\right) \Gamma_{i, i+1}-c_{i+1}\left(1-c_{i}\right) \Gamma_{i+1, i}\right],
$$


where $\Gamma_{i, i+1}$ is the probability per unit time that an A atom in layer $i$ exchanges its position with a B atom in the layer $i+1$ and $z_{v}$ is the vertical coordination number. For the jump frequency an Arrhenius-type temperature dependence is assumed:

$$
\Gamma_{i, i+1}=v \exp \left(-E_{i, i+1} / k T\right)
$$

where $v$ denotes the attempt frequency, $k$ and $T$ are the Boltzmann's constant and the temperature, respectively, $E_{i, i+1}$ is the activation energy barrier of an exchange between an A atom being in layer $i$ and a $\mathrm{B}$ atom being in layer $(i+1)$, which can be chosen in different ways (but satisfying the steadystate condition) as was shown by Martin [11]. As we have shown [12] one of the most adequate choices is the following:

$$
E_{i, i+1}=\hat{E}^{0}-\alpha_{i}+\varepsilon_{i} \quad \text { and } \quad E_{i+1, i}=\hat{E}^{0}-\alpha_{i}-\varepsilon_{i},
$$

where $\hat{E}^{0}$ is a composition independent term containing the saddle point energy, and:

$$
\begin{aligned}
& \alpha_{i}=\left[z_{v}\left(c_{i-1}+c_{i+1}+c_{i}+c_{i+2}\right)+z_{l}\left(c_{i}+c_{i+1}\right)\right] M \\
& \varepsilon_{i}=\left[z_{v}\left(c_{i-1}+c_{i+1}-c_{i}-c_{i+2}\right)+z_{l}\left(c_{i}-c_{i+1}\right)\right] V
\end{aligned}
$$

Here $z_{l}$ is the lateral coordination number, $M=\left(V_{A A^{-}} V_{B B}\right) / 2$ and $\left.V=V_{A B^{-}} V_{A A}+V_{B B}\right) / 2$, where $V_{X Y}$ are the nearest neighbour pair interaction energies between species $X$ and $Y(X, Y=A$ or $B)$ in the framework of a pair-interaction model. However, as was shown also in [12], $M$ in $\alpha_{i}$ determines the strength of the composition dependence of the transition rates, whereas $V$ in $\varepsilon_{\mathrm{i}}$ is the regular solid solution parameter [13], proportional to the heat of mixing and measures the phase separating $(V>0)$ or ordering $(V<0)$ tendency. Thus e.g. $M$ can be determined from the composition dependence of $D$ : $M=m k T / 2 Z$, where $Z=2 z_{v}+z_{l}$ and $D(c)=D(0) \exp (m c)$ and $m^{\prime}=m \lg (e)$ gives in orders of magnitude the difference between the diffusion coefficients in the pure $A$ and $B$ matrixes. For example $m$ is about 10 and 16 in the $\mathrm{Ni}-\mathrm{Cu}$ and $\mathrm{Mo}-\mathrm{V}$ systems respectively [14-16], which means that the diffusion is about 4-5 orders of magnitude faster in the $\mathrm{Cu}$ matrix than in the Ni, i.e. $m^{\prime}=4-5$.

\section{Results of computer simulations}

The computer simulations have shown that the initially sharp interface between the deposited thin film and the substrate may remain sharp even during the dissolution process basically for two reasons. Either because the solubility of the deposit and the substrate atoms are restricted in each other (phase separation) or due to the diffusion asymmetry. Why the phase separation tendency keeps the interface abrupt does not need justification, however, how the diffusion asymmetry can do the same needs some explanation.

A diffusion asymmetry means that in a diffusion couple the diffusion is much faster in one matrix than in the other one. If for example the diffusion is much faster in the substrate than in the deposited film only the deposit atoms at the interface may dissolve into the substrate and diffuse away fast, whereas the substrate atoms cannot penetrate into the deposit. As a result the deposit layer dissolves quasi layer-by layer into the substrate, and the interface remains sharp during the dissolution process. (Fig. 2) It is worth noting here that sharp interface shift has also been proved by Auger depth profiling technique in Si-Ge system. [17] 


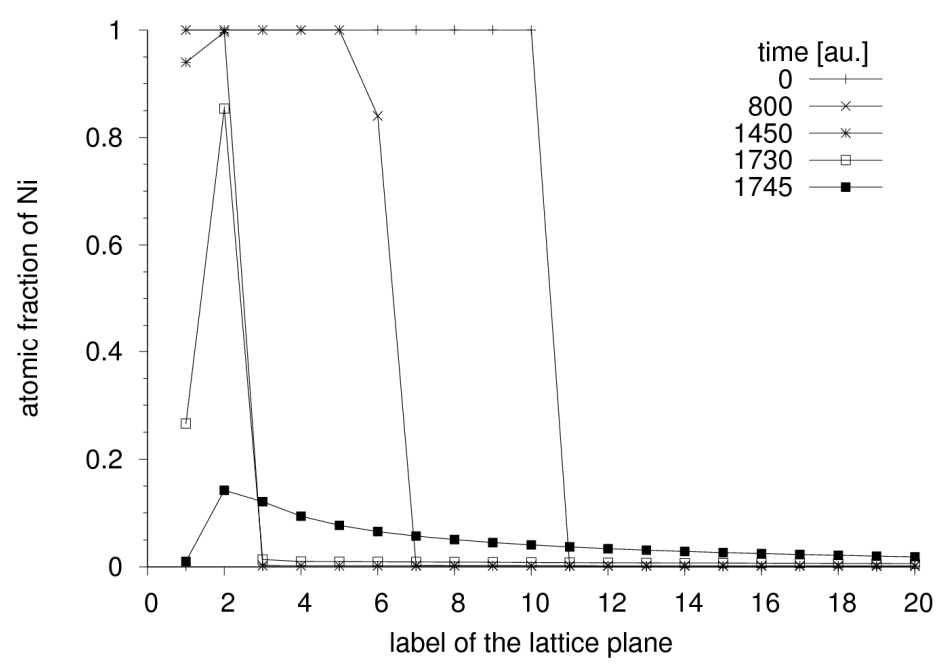

Fig. 2, Quasi layer-by-layer dissolution of 10 atomic layers $\mathrm{Ni}$ into $\mathrm{Cu}(111)$ at different diffusion times giecn in arbitrary units (au.). The diffusion is orders of magnitude faster in the $\mathrm{Cu}$ substrate than in the Ni deposit. When the interface reaches the near surface region, the $\mathrm{Cu}$ substrate atoms start to segregate.

It is known from Fick's phenomenological laws that during annealing of a diffusion couple the displacement of a plane with constant composition is proportional to $t^{1 / 2}$. However, it has been shown from computer simulations that this rule can be violated on the nanoscale either in completely [5] or restricted miscible systems [14].

In order to investigate the interface shift, Eqs. (6-10) have been solved numerically [5, 14]. For the description of the interface shift, the following initial condition was used: on the left- and righthand side of the interface all the atomic planes were occupied only by $A$ atoms as well as $B$ atoms, respectively. In order to avoid 'finite effects', a continuous boundary condition was applied, i.e. when the composition of the atomic planes at the either ends of the sample were changed 10 pure $A$ or $B$ atomic planes were added to the sample [14]. The position of the interface was determined by the plane with the composition 0.5: it can obviously lie between two atomic planes. After determining this position $(p)$, its logarithm versus the logarithm of the time $(\log p \propto \log t)$ was plotted. Fitting a straight line to the data, its slope gave the power of the function describing the shift of the interface: it is called kinetic exponent and denoted by $k_{c}$. Obviously for parabolic interface shift $k_{c}=0.5$. Thus if the kinetics is non-Fickian, $k_{c} \neq 0.5$ or the data do not fit on a straight line on the $\log p \propto \log t$ plot.

In order to demonstrate the effects of the composition dependence of diffusion coefficients on the kinetics of the interface shift both in ideal and phase separating systems, the parameters $m^{\prime}$ and $V$ (or $V / k T$ ) were changed during the calculations.

Figure 3 shows the initial values of the kinetic exponent, $k_{c}$, obtained by fitting to the interval corresponding to dissolution of the first 5 planes versus $V / k T$ for different $m^{\prime}$ values. It can be seen that $k_{c}$ is almost constant and, as it is expected, is very close to 0.5 for small $\mathrm{m}^{\prime}$. The discussion of the small deviations form the 'pure' parabolic growth is given in [14]. At the same time, the deviation from the square root kinetics increases with increasing $m^{\prime}$ for a fixed value of $V / k T$. 


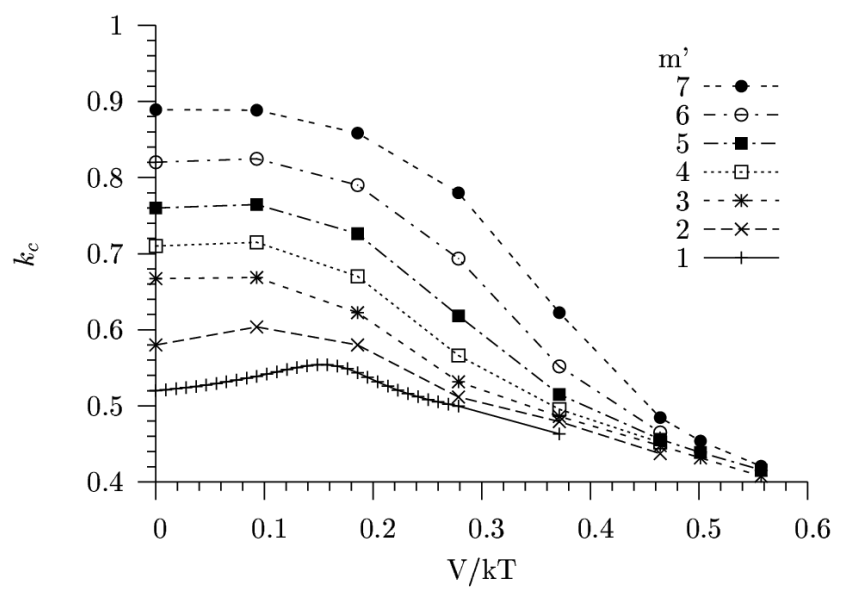

Fig. 3, Kinetic exponent versus $V / k T$ for different m' values.

The deviation from the parabolic law is a real "nano-effect", because after dissolving a certain number of layers, i.e. in long time or macroscopic limit, the interface shift returns to the parabolic behaviour independently of the input parameters (Figure 4).

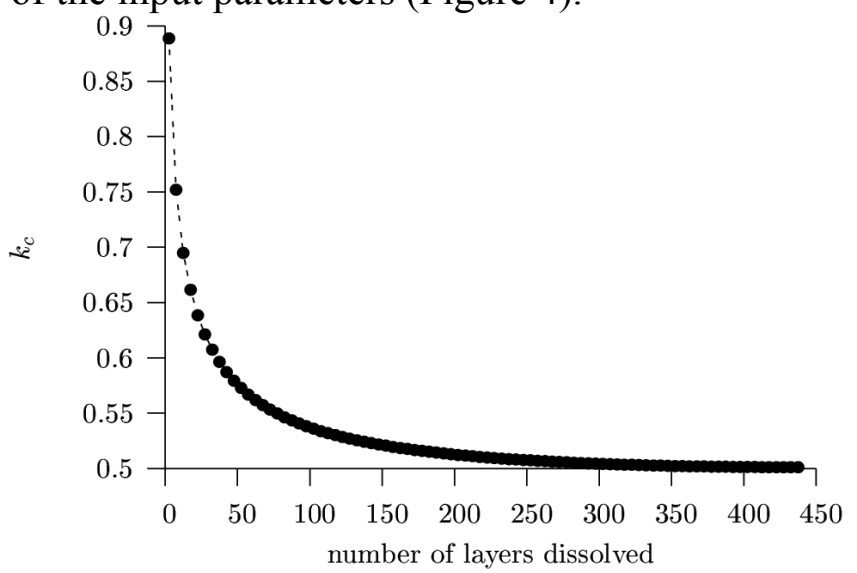

Fig. 4, Change of $\mathrm{k}_{\mathrm{c}}$ during dissolution $\left(m^{\prime}=7, V / k T=0.09\right)$. The more layers are dissolved the closer the value of $k_{c}$ is to 0.5

It has been shown [18], that this transition can be understood from the analysis of the atomic currents in the different parts of the sample. In principle three currents can be distinguished: i) $J_{\alpha}$ in matrix $A$, where the diffusion is very slow, ii) $J_{I}$ across the interface region and iii) $J_{\beta}$ in matrix $B$, where the diffusion is fast (Fig. 5). However, $J_{\alpha}$ can be neglected, because practically there is no diffusion in matrix $A$. Moreover, at the beginning of the kinetics, when the composition gradient is very large, the flux in the $B$-rich phase ( $\beta$ phase) is larger than across the interface $\left(J_{I}<J_{\beta}\right)$. In this stage $J_{I}$ controls the diffusion. During the process $J_{\beta}$ becomes smaller and smaller because the tail of the composition profile in the $\beta$ phase grows more and more resulting in the decrease of the gradient of the composition. Although, $J_{I}$ also decreases with increasing time/number of layer dissolved, but $J_{\beta}$ decreases much faster. As a result, in a certain moment $J_{\beta}$ becomes smaller than the $J_{I}$, and from this point $J_{\beta}$ is the rate limiting. Thus the transition time or thickness must be deduced from the condition $J_{I}=J_{\beta}$ which has to be fulfilled at the interface.

It is worth mentioning that from the analysis of the currents an atomistic explanation of the phenomenological interface transfer coefficient $(K)$ can also be done, which has been missing in the reaction diffusion literature. Following the phenomenological definition of $K, J_{I}=K\left(c_{e}-c\right)$ ( $c$ and $c_{e}$ denote the current and the equilibrium composition at the interface, respectively) and comparing this to the $J_{I}$ in the discrete model [18]

$$
K \cong v z_{v} \exp \left(-Q_{K} / k T\right)
$$


with $Q_{K}=E_{0}+z_{l} V+M Z=E_{0}+z_{l} V+m k T / 2$. In fact $K$ is proportional to the jump frequency from the $A$ rich phase to the $B$-rich one. This is different from the jump frequency in the $B$-rich phase, where the jump frequencies are larger at the same temperature, just because these frequencies depend on the composition. If there is an abrupt interface present at the very beginning of the intermixing, then the interface transfer controls the flux only until the gradients will be large enough to establish the diffusion flux $J_{\beta}$ larger than $J_{I}$. In fact the magnitude of the finite value of $J_{I} \cong K$ gives the permeability of the interface and it is determined by the $m$ and $V / k T$ parameters.

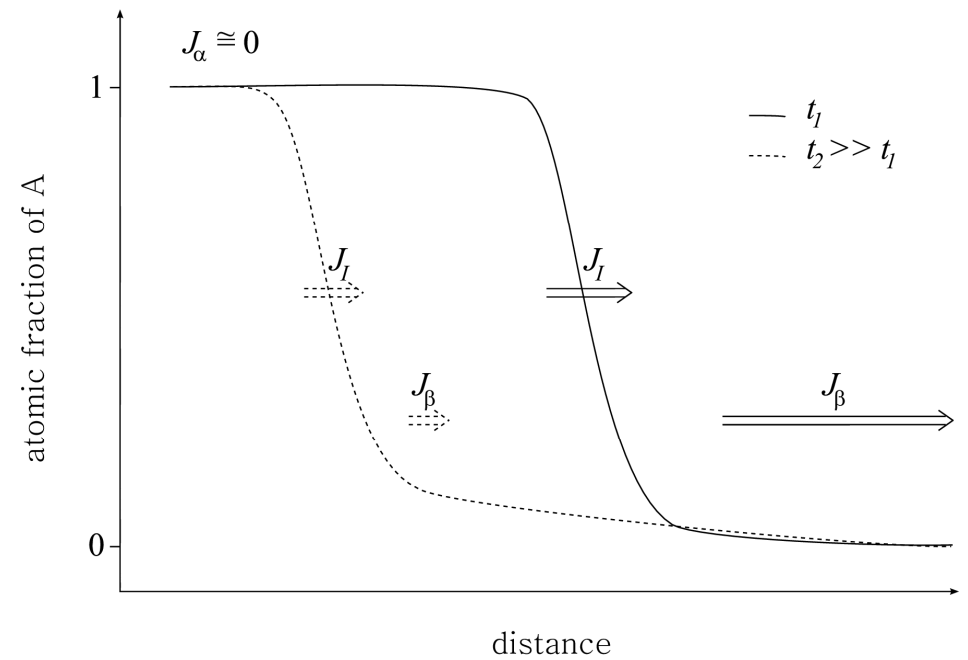

Figure 5. Schematic of the composition profile and the atomic fluxes in the linear $\left(t_{1}\right.$, solid line) and parabolic $\left(t_{2}>>t_{1}\right.$, dashed line) kinetic regimes. The length of the arrows illustrates the intensity of the fluxes.

Although it is almost exclusively accepted in the literature that linear growth kinetics are the result of interface reaction control, our results suggest that the non-parabolic growth of a reaction layer on the nanoscale cannot be automatically interpreted by interface reaction. In the light of the above observations it seems desirable to reformulate our results in a form of the linear-parabolic, or Deal and Groves [19], law routinely used in the interpretation of experimental data for processes showing a transition between interface reaction and diffusion control [20]. According to [21] the linear-parabolic transition or crossover thickness can be estimated from the following expression:

$$
X^{\prime^{*}} \cong c_{\beta} D_{\beta} / 2 K
$$

where $c_{\beta}$ and $D_{\beta}$ are the composition and the diffusion coefficients in the $\beta$ phase.

Finally, it is worth mentioning our very recent results obtained for ordering systems, i.e. in which a new phase forms and growths at the interface of a diffusion couple. We have shown that stoichiometric ordered phases at the interface of a bilayer may dissolve - even completely - during the annealing process. Later the ordered phase re-forms but highly of-stoichiometricaly [22] (Fig. 6). It was also discussed that the phase growth kinetics (also the shift kinetics of the interface bordering the growing ordered phase) is anomalous due to the diffusion asymmetry and not because of the interface reaction control usually mentioned in solid state reactions [23]. 


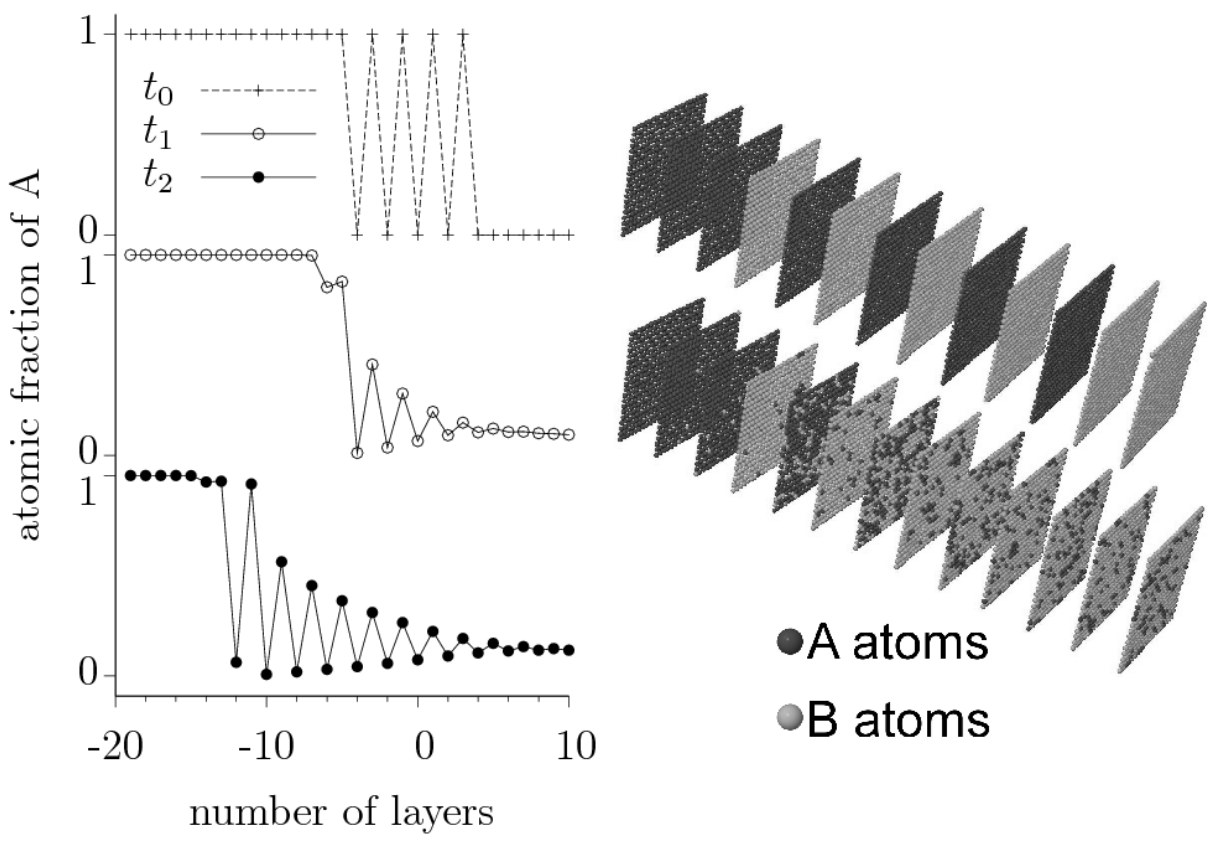

Fig. 6, Dissolution and off-stoichiometric regrowth of the $A B$ phase in asymmetric diffusion [BCC(100)]. Left panel (KMF): Time evolution of the composition profile. The AB phase dissolves into the B matrix $\left(t_{0}, t_{1}\right)$ and starts to regrow for $t>t_{1}$. However the order is not uniform $\left(t_{2}\right)$. Right panel (KMC): Atomistic view of the initial state and after some time when $A B$ is somewhat dissolved (small part of the $\mathrm{KMC}$ cell is shown; lattice planes are detached for better visualisation).

\section{Experimental}

The effects discussed in the previous sections cannot be investigated in classical diffusion measurement setups because very small amount of materials moves and the characteristic length scale is very short. Surface analytical techniques are sensitive enough to detect very small changes in composition but limited in depth probing. Thus specially designed sample structures and experimental setups were needed. Basically two types of measurements were carried out.

To study grain-boundary diffusion, a polycrystalline film of $10-20 \mathrm{~nm} / \mathrm{substrate}$ bilayer structure was used. The surface accumulation kinetics of substrate atoms was monitored by Auger electron spectroscopy (AES) or X-ray photoelectron spectroscopy (XPS).

To investigate the interface shifts kinetics, the main idea was to prepare a thin deposit onto the surface of a substrate, where the deposit was thin enough $(\sim 3-5 \mathrm{~nm})$ to be able to detect the signal coming from the substrate by AES or XPS, and not only that of the deposit. As will be discussed in next sections, it is possible to determine the position of the buried film/substrate interface form the ratio of the film and substrate intensities, i.e. to calculate the interface shift kinetics during interdiffusion.

To characterize the samples and to get complementary information about the processes, further experimental techniques were used: scanning tunneling microscope (STM), ultraviolet photoemission spectroscopy (UPS), low-energy electron diffraction (LEED), transmission electron microscope (TEM), secondary neutral mass spectrometry (SNMS), etc.

The samples were prepared by magnetron sputtering and evaporation techniques.

The technical details and the experimental conditions are given in the references listed in the next sections.

\section{Hwang-Balluffi type experiments}

In this section the results of our low temperature diffusion measurements are shown, which demonstrate the usability of the surface analytical technique for this purpose. 
The main idea is to measure the surface accumulation kinetics of the substrate atoms $\left(c_{s}\right.$ vs. time, see Eq. 1) by a surface analytical technique (e.g. AES or XPS). Then using Eq. $5 \omega$ ' can be determined [6].

The Hwang-Balluffi method was applied for two systems. One the $\mathrm{Cu} / \mathrm{Ag}$ system is phase separating, whereas the other one, the $\mathrm{Pd} / \mathrm{Ag}$, is ideal.

$\mathrm{Cu} / \mathrm{Ag}$ system. From the $\mathrm{Ag}$ and $\mathrm{Cu}$ Auger signals measured on the surface, the temperature dependence of the parameter $\omega^{\prime}$ for $\mathrm{Ag}$ grain-boundary diffusion in $\mathrm{Cu}$ have been determined in $\mathrm{C}$ kinetic regime over the temperature range of 393-428 K. Figure 7a shows the Arrhenius plot of this parameter, which can be given by

$$
\omega^{\prime}=1.49 \times 10^{-4} \exp \left[-\frac{(124 \pm 15) \mathrm{kJ} / \mathrm{mol}}{R T}\right] \frac{1}{\mathrm{~s}}
$$

These values have been compared with triple products, $P=\delta k_{b} D_{b}$, determined in the temperature range 584-804 $\mathrm{K}$ by Bernardini et.al [24] using the radio tracer technique in B-kinetics regime and the temperature dependence of the surface segregation factor has been extracted:

$$
k_{s}=\frac{1}{\delta_{s}} 2.48 \times 10^{-10} \exp \left(\frac{34 \pm 16 \mathrm{~kJ} / \mathrm{mol}}{R T}\right)
$$

Pd/Ag system. 2-10 nm of Pd was evaporated onto a $\mathrm{Ag}(111)$ single crystal. The samples were heat treated in the temperature range of 463-563 K; for details see Balogh et al. in this volume [25]. Figure $7 \mathrm{~b}$ shows the Arrhenius plot of this parameter, which can be given by

$$
D_{b}=2.066 \times 10^{-10} \exp \left[-\frac{(95.5 \pm 7.7) \mathrm{kJ} / \mathrm{mol}}{R T}\right] \frac{\mathrm{m}^{2}}{\mathrm{~s}}
$$
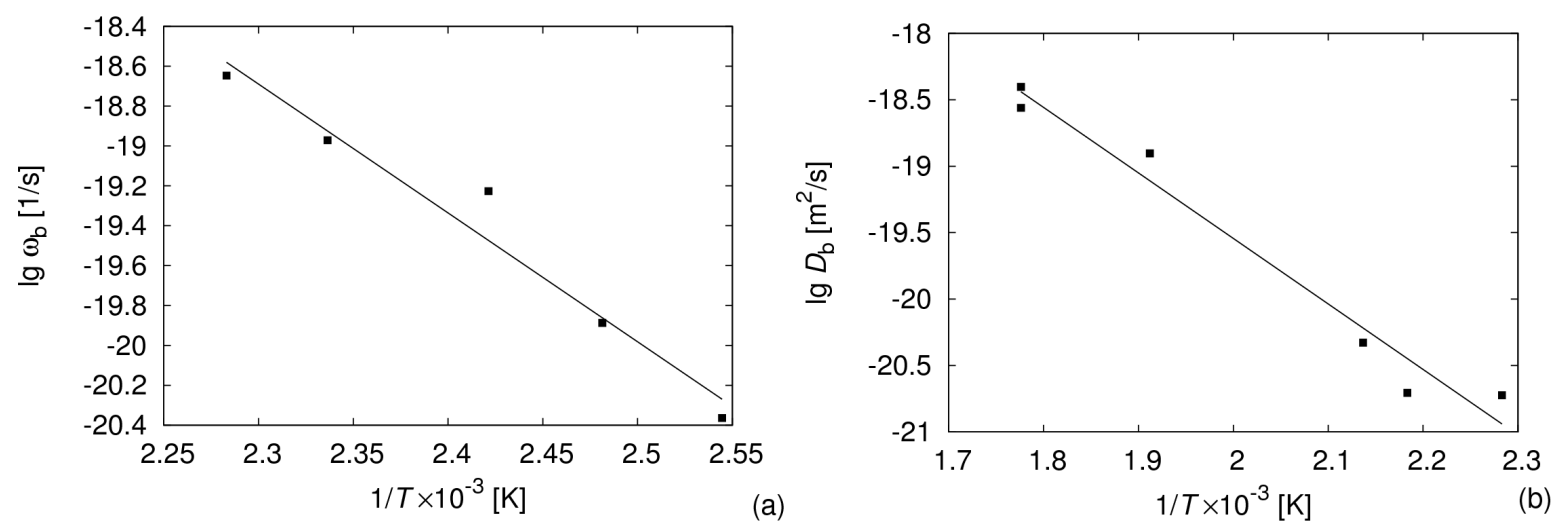

Fig.7, Arrhenious plot of the measured data: (a) $\mathrm{Cu} / \mathrm{Ag}$ and (b) $\mathrm{Pd} / \mathrm{Ag}$ systems.

\section{Experiments for anomalous interface shift kinetics.}

This section presents examples of experimental proofs of the phenomena predicted by computer simulations. As the effects are present only on the nanoscale, their observation needs techniques able to resolve composition profiles on the atomic level. As this section it is demonstrated that surface analytical techniques may be able to reveal very sort length scale diffusion processes in suitable experimental setup.

The main idea in these experiments is to prepare a thin deposit onto the surface of a substrate, where the deposit is thin enough to be able to detect the signal coming from the substrate, i.e. the deposit is "transparent" for the experimental technique used. In this case the thickness of the deposit can be calculated from the ratio of the deposit and substrate signal intensities $\left(I_{\mathrm{dep}} / I_{\text {sub }}\right)$. During annealing, if the interface remains abrupt, from the change of $I_{\text {dep }} / I_{\text {sub }}\left(I_{\text {dep }}\right.$ decreasies, whereas $I_{\text {sub }}$ 
increases in time) it is possible to determine how the thickness of the deposit decreases with the time. The deposit thickness can easily be converted to interface position; i.e. the $\log p \propto \log t$ function can be plotted, of which slope is just equal to $k_{\mathrm{c}}$. As was mentioned in the theorysimulation section, for normal Fickian kinetics $k_{\mathrm{c}}=0.5$, therefore if the $\log p \propto \log t$ provides a nonlinear function or a linear but with a slope different from 0.5 , the kinetics is anomalous (nonFickian).

Since according to the results of computer simulations different $k_{c}$ values are expected depending on the strength of the diffusion asymmetry $\left(m^{\prime}\right)$ and the phase separation tendency $(V)$, different systems have been investigated: an ideal $(\mathrm{Ni} / \mathrm{Cu})$ and a phase separating $(\mathrm{Ni} / \mathrm{Au})$ system. Moreover, order to the check whether the anomalous interface shift kinetics is independent of the sample structure and diffusion mechanisms or not, measurements in the ideal amorphous $\mathrm{Si} / \mathrm{Ge}$ system were also performed. Furthermore, for the comparison of the results on the same system but with different structure, measurements in crystalline $\mathrm{Si} / \mathrm{Ge}$ samples have also been repeated.

$\mathbf{N i} / \mathbf{C u}(\mathbf{1 1 1})$ system $(\boldsymbol{m}$ ’ $\mathbf{5}, \boldsymbol{V} \cong \mathbf{0}$ - ideal). To investigate the interface shift kinetics in $\mathrm{Ni} / \mathrm{Cu}$ system 3-14 monolayers $\mathrm{Ni}$ onto a $\mathrm{Cu}(111)$ single crystal were deposited [3]. The samples were heat treated in the temperature range of $600-730 \mathrm{~K}$ and the dissolution process was followed by in-situ AES measurements. From the analysis of the change of the $\mathrm{Ni}(848 \mathrm{eV})$ and $\mathrm{Cu}(920 \mathrm{eV})$ signals, the interface shift kinetics were determined and it was obtained that the interface shift is proportional to the time $\left(k_{\mathrm{c}} \cong 1\right)$ and not to its square root as predicted by Fick's theory.

Moreover, it was shown that if the interface shift kinetics is proportional to the time, the speed of the interface shift is constant - which can be determined from the interface shift kinetics easily and from the interface shift speed an intrinsic diffusion coefficient of $\mathrm{Ni}$ in a $\mathrm{Ni}_{78} \mathrm{Cu}_{12}$ alloy; which is just equal to the $K$ interface transfer coefficient:

$$
D \equiv K=2.9 \exp \left(-\frac{297 \pm 62 \mathrm{~kJ} / \mathrm{mol}}{R T}\right) \mathrm{m}^{2} / \mathrm{s}
$$

$\mathrm{Ni} / \mathrm{Au}(111)$ system ( $m^{\prime} \cong \mathbf{6}, V \cong \mathbf{0 . 0 1 9} \mathrm{eV}$ - phase separating). In order to check the validity of the computer simulation results obtained also for phase separating systems, the above experiments were repeated but with $\mathrm{Ni} / \mathrm{Au}$ system where the solubility is $3 \%$ at about $T=680 \mathrm{~K}$ and $V=0.019 \mathrm{eV}$ [3]. Here $3 \mathrm{~nm}$ thick Ni was deposited onto the surface of a $\mathrm{Au}(111)$ single crystal and the dissolution process was investigated by in-situ XPS measurements in the temperature range of $643-733 \mathrm{~K}$. The change of the ratio of the integrated Au- $4 \mathrm{f}$ and Ni-2p core line intensities was expected to increase with time for both processes, i.e. for segregation of $\mathrm{Au}$ atoms on top of the $\mathrm{Ni}$ film as well as for dissolution of $\mathrm{Ni}$ atoms into the $\mathrm{Au}$ single crystal, respectively. Obviously, a monotonous increase can indeed be recognized in Fig. 8. However, there clearly exist two different time domains indicating a fast change of this ratio at the beginning (up to about $60 \mathrm{~min}$ ) and a slow, but still monotonous increase for longer times.

On the basis of STM, UPS, XPS and LEED studies it was concluded that closed, textured nanocrystalline Ni layers were obtained with grains preferentially oriented in (111) direction and a lateral size of $d \cong 10 \mathrm{~nm}$. Thus the first time domain was identified as being due to the fast diffusion of $\mathrm{Au}$ along the grain boundaries and their segregation on the top of the Ni deposit layer (HwangBalluffi scenario). From this part, we have determined the value of $D_{\mathrm{b}} k_{\mathrm{b}} / k_{\mathrm{s}}$, which was $2 \times 10^{-20} \mathrm{~m}^{2} / \mathrm{s}$ at $643 \mathrm{~K}$. For Ni diffusion via Ni twist grain-boundaries the value of $D_{\mathrm{b}}$ is known to be $1.35 \times 10^{-19} \mathrm{~m}^{2} / \mathrm{s}$ from literature [26]. 


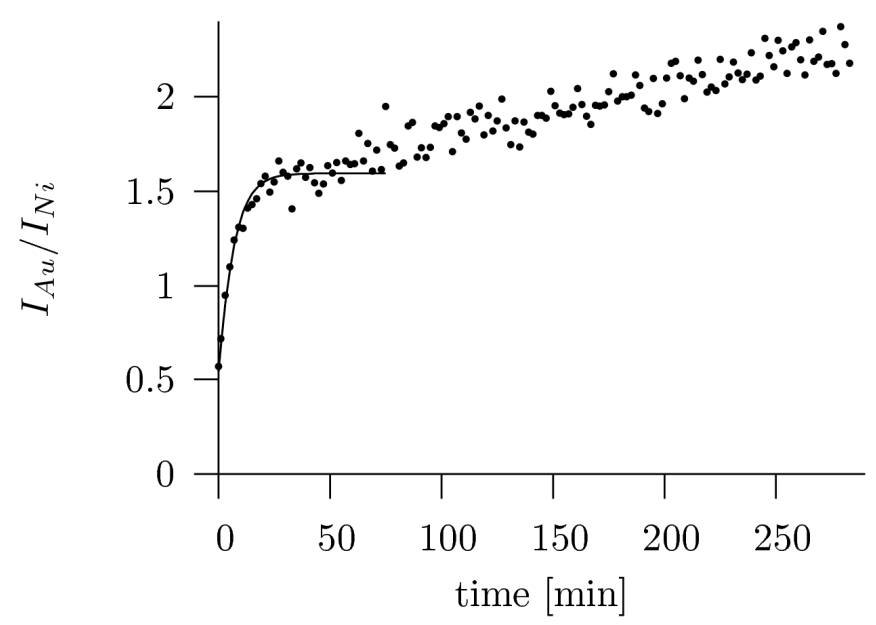

Fig. 8, Time evolution of the ratio between the Au- $4 \mathrm{f}$ and the Ni-2p core line intensities measured at $\mathrm{T}=643 \mathrm{~K}$ (dots). The solid line represents the fit of the first time domain (Hwang-Balluffi type) [3].

The latter time domain reflects the interface shift during the dissolution of $\mathrm{Ni}$ atoms into the $\mathrm{Au}$ single crystal. From this part the values of $k_{\mathrm{c}}$ could be deduced at different temperatures: $k_{\mathrm{c}} \cong 0.6$ 0.7. These values show that kinetics is anomalous in this case, too. Furthermore, the experiments suggest a value of $m^{\prime} \cong 6$ within the investigated temperature range and this, together with $V=0.019 \mathrm{eV}$, indicates an excellent agreement between the simulations and experiment (Fig. 9).

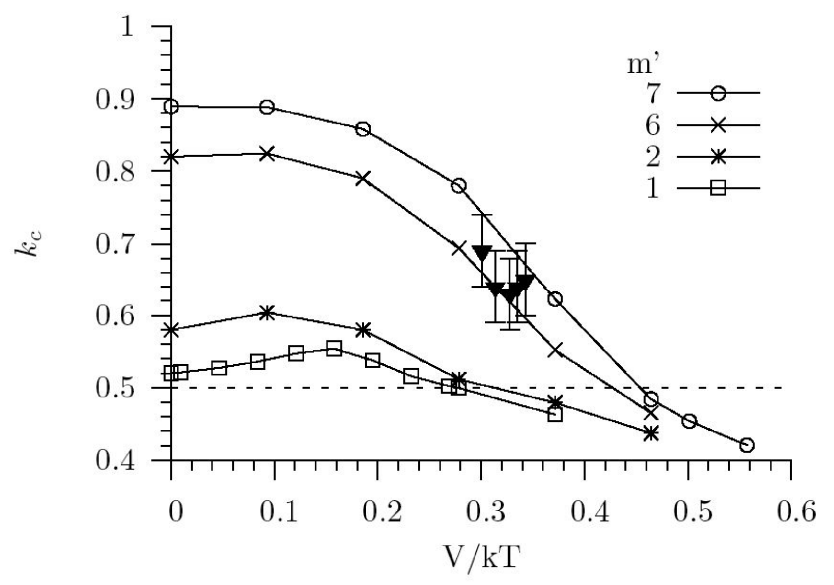

Fig. 9, Kinetic exponents $k_{\mathrm{c}}$ versus $V / k T$ for different $m$ ' values as simulated and as measured. The experimentally determined data are inserted as solid triangles including error bars representing the uncertainty of the parameter fit. The classical diffusion behavior is indicated by the horizontal dashed line.

Amorphous Si/Ge system ( $\boldsymbol{m}^{\prime} \cong \mathbf{3}, \boldsymbol{V}=\mathbf{0}$ - ideal). As was presented above, several theoretical and experimental studies of diffusion kinetics on the nanoscale have shown that the time evolution differs from the classical Fickian law. However, all work was based on crystalline samples or models, so far. To reveal if the kinetic anomalous in amorphous systems, the dissolution kinetics of a thin amorphous Si layer into amorphous Ge was carried out [2]. The interface shift was monitored by AES and XPS techniques. Figure 10 shows how the interface shifts in time. Two domains are identified corresponding to two different lines having different slopes. This means that the kinetic exponents are different for the two domains. Initially $k_{\mathrm{c}}$ was found at $0.7 \pm 0.1$, whereas in the later domain 0.5 . Therefore not only the anomalous part of the diffusion process could be observed but also the transition back to the classical Fickian behaviour. 


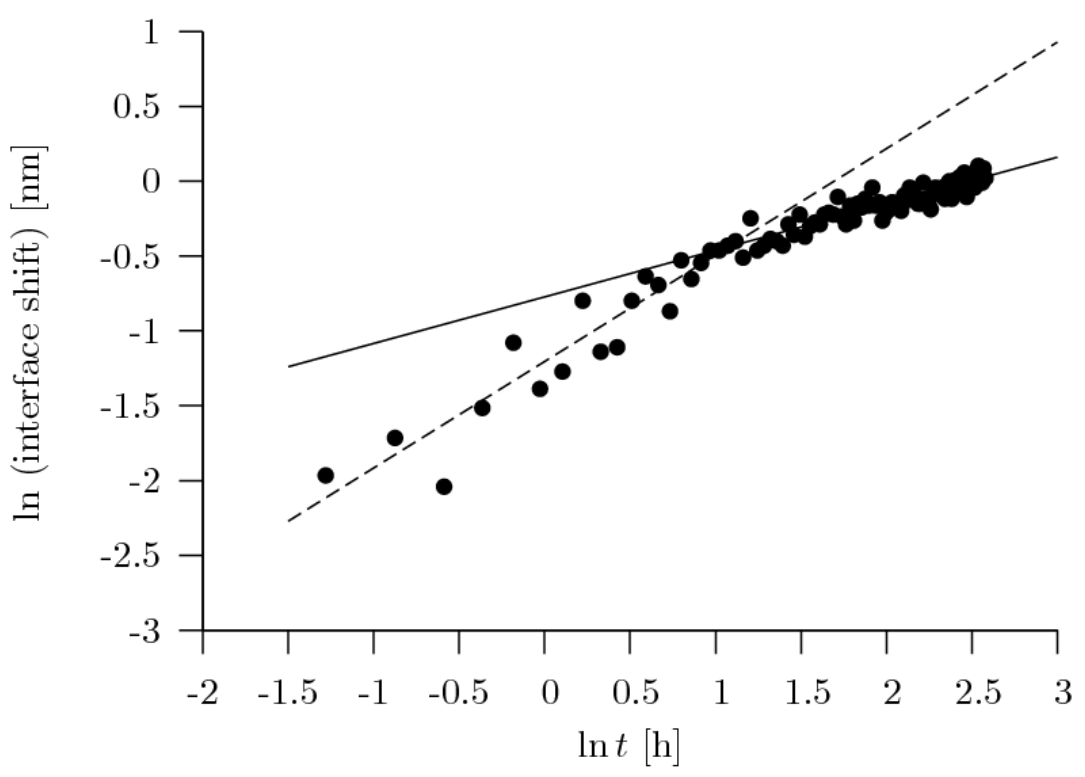

Fig. 10, Interface shift vs time on log-log scale. The non-Fickian first part as well as the transition area are clearly visible.

Crystalline $\mathrm{Si} / \mathrm{Ge}(\mathbf{1 1 1})$ system $\left(\boldsymbol{m}^{\prime} \cong 4-5, V=0\right)$. To be able to compare the results in case of the same system but with different structures, previously discussed measurements have been repeated, but in crystalline $\mathrm{Si} / \mathrm{Ge}$ in the temperature range of 740-755 K. 2-4 nm Si was deposited on the top of a $\mathrm{Ge}(111)$ substrate and it was found that $k_{\mathrm{c}}$ of $0.85 \pm 0.1$. The diffusion lengths were around $2 \mathrm{~nm}$ in two experiments - this is more than the largest non-Fickian $\rightarrow$ Fickian transition length observed for the amorphous system - but no any change of $k_{\mathrm{c}}$, indicating larger transition length than in the case of the amorphous system, have been observed. This is consistent with the larger $m$ ' of this system.

Crystalline-Co/amorphous-Si system. In this system the literature data are contradictory for $m$ ', while $\mathrm{V}<0$ (ordering) [23, 27]. CoSi growth has been measured by XRD and 4WR in Co/Si system. The phase growth kinetics and also the shift kinetics of the interface bordering the growing ordered phase have been found anomalous. It is - very probably - due to the diffusion asymmetry and not because of the interface reaction control usually mentioned in solid state reactions. For the details of this work see also the article of Cserháti et al. in this volume [27].

\section{Summary}

In this review paper it has been demonstrated that surface analytical techniques are adequate for studying diffusion processes in which very small amount of materials moves as compared to classical diffusion experiments. It has been illustrated that accurate Arrhenius functions can be measured at extremely low temperatures in C-kinetic regime. Moreover, in case of suitable sample geometry, nanoscale motions of buried internal interfaces can be followed. It has been shown that the diffusion asymmetry influences the diffusion kinetics and interface morphology on the nanoscale independently of the sample structure, the chemical properties and diffusion mechanism.

\section{Acknowledgements}

This work was supported by the OTKA Board of Hungary (No. K67969, K61253). 


\section{References}

[1] Z. Balogh, Z. Erdélyi, D.L. Beke, A. Portavoce, Ch. Girardeaux, J. Bernardini, A. Roland: submitted to Appl. Surf. Sci. (2008)

[2] Z. Balogh, Z. Erdélyi, D.L. Beke, G.A. Langer, A. Csik. H.-G. Boyen, U. Wiedwald, and P. Ziemann, A. Portavoce, Ch. Girardeaux: Appl. Phys. Letters Vol. 92 (2008), p. 143104

[3] G. L. Katona, Z. Erdélyi, D. L. Beke, Ch. Dietrich, F. Weigl, H.-G. Boyen, B. Koslowski, P. Ziemann: Phys. Rev. B Vol. 71 (2005), p. 115432

[4] Z. Erdélyi, G. L. Katona, D. L. Beke: Phys. Rev. B Vol. 69 (2004), p. 113407

[5] Z. Erdélyi, Ch. Girardeaux, Zs. Tőkei, D. L. Beke, C. Cserháti, A. Rolland: Surface Science Vol. 496 (2002), p. 129

[6] Z. Erdélyi, Ch. Girardeaux, G. A. Langer, D. L. Beke, A. Rolland, J. Bernardini: J. of Appl. Phys. Vol. 89 (2001), p. 3971

[7] Z. Erdélyi, Ch. Girardeaux, G. A. Langer, L. Daróczi, A. Rolland, D. L. Beke: Applied Surface Science Vol. 162-163 (2000), p. 213

[8] J.C.M. Hwang, J.D. Pan, R.W. Balluffi : J. Appl. Phys. Vol. 50 (1979), p. 1339

[9] I. Kaur, Yu Mishin and Gust, Fundamentals of Grain and Interphase Boundary Diffusion, Third enlarged edition, John Wiley \& Sons Ltd (1995)

[10] J.C.M. Hwang, J.D. Pan, R.W. Balluffi: J. Appl. Phys. Vol. 50 (1979), p. 1335

[11] G. Martin: Phys. Rev. B Vol. 41 (1990), p. 2279

[12]Z. Erdélyi, D.L. Beke: Phys. Rev. B Vol. 70 (2004), p. 245428

[13]D.L. Beke, C. Cserháti, Z. Erdélyi, I.A. Szabó: "Segregation in Nanostructures", in Nalwa, H.S. (Ed.), Advances in Nanophase Materials and Nanotechnology: Vol. Nanoclusters and Nanocrystals, American Scientific Publisher, Stevenson Ranch, California (2002)

[14]Z. Erdélyi, G.L. Katona, D.L. Beke: Phys. Rev. B Vol. 69 (2004), p. 113407

[15]Z. Erdélyi, I.A. Szabó, D.L. Beke: Phys. Rev. Lett. Vol. 89 (2002), p. 165901

[16]Z. Erdélyi, M. Sladecek, L.-M. Stadler, I. Zizak, G.A. Langer, M. Kis-Varga, D.L. Beke, B. Sepiol: Science Vol. 306 (2004), p. 1913

[17]A. Csik, G.A. Langer, D.L. Beke, Z. Erdélyi, M. Menyhárd, A. Suloyk: J. Appl. Phys. Vol. 89 (2001), p. 804

[18]D.L. Beke, Z. Erdélyi: Phys. Rev. B Vol. 73 (2006), p. 035426

[19]B. E. Deal, A. Groves: J. Appl. Phys. Vol.36 (1965), p.3770

[20]F. Nemouchi, D. Mangelick, C. Bergmann, P. Gas, U. Smith: Appl. Phys. Lett. Vol.86 (2005), p.041903

[21]D.L. Beke, Z. Erdélyi, Z. Balogh, Cs. Cserháti, G.L. Katona: proceedings of Diffusion in Solids and Liquides 2008 (DSL-2008) conference (in print)

[22]Z. Erdélyi, D.L. Beke, A. Taranovskyy: Appl. Phys. Lett. Vol. 92 (2008), p. 133110

[23]C. Cserháti, Z. Balogh, A. Csik, G.A. Langer, Z. Erdélyi, GY. Glodán, G.L. Katona, D.L. Beke,

I. Zizak, N. Darowski, E. Dudzik, R. Feyerherm: J. Appl. Phys. Vol. 104 (2008), p. 024311

[24] J. Bernardini, Zs. Tôkei, D.L. Beke, Phil. Mag. A Vol. 73 (1996), 237

[25]Z. Balogh et al. (this volume)

[26]H. Mehrer, Landolt-B“ornstein, New Series (Berlin: Springer-Verlag, 1990), chap. 12.

[27]C. Cserháti et al. (this volume) 


\section{Diffusion in Materials}

doi:10.4028/www.scientific.net/DDF.289-292

Thin Film Dissolution into Semi-Infinite Substrates: Surprising Interface Kinetics and Dissolution Modes

doi:10.4028/www.scientific.net/DDF.289-292.573

\section{References}

[1 ] Z. Balogh, Z. Erdélyi, D.L. Beke, A. Portavoce, Ch. Girardeaux, J. Bernardini, A. Roland: submitted to Appl. Surf. Sci. (2008)

[2 ] Z. Balogh, Z. Erdélyi, D.L. Beke, G.A. Langer, A. Csik. H.-G. Boyen, U. Wiedwald, and P. Ziemann, A. Portavoce, Ch. Girardeaux: Appl. Phys. Letters Vol. 92 (2008), p. 143104

[3 ] G. L. Katona, Z. Erdélyi, D. L. Beke, Ch. Dietrich, F. Weigl, H.-G. Boyen, B. Koslowski, P. Ziemann: Phys. Rev. B Vol. 71 (2005), p. 115432 doi:10.1103/PhysRevB.71.115432

[4 ] Z. Erdélyi, G. L. Katona, D. L. Beke: Phys. Rev. B Vol. 69 (2004), p. 113407 doi:10.1103/PhysRevB.69.113407

[5 ] Z. Erdélyi, Ch. Girardeaux, Zs. Tkei, D. L. Beke, C. Cserháti, A. Rolland: Surface Science Vol. 496 (2002), p. 129 doi:10.1016/S0039-6028(01)01571-0

[6 ] Z. Erdélyi, Ch. Girardeaux, G. A. Langer, D. L. Beke, A. Rolland, J. Bernardini: J. of Appl. Phys. Vol. 89 (2001), p. 3971 doi:10.1063/1.1346658

[7 ] Z. Erdélyi, Ch. Girardeaux, G. A. Langer, L. Daróczi, A. Rolland, D. L. Beke: Applied Surface Science Vol. 162-163 (2000), p. 213

doi:10.1016/S0169-4332(00)00194-X

[8 ] J.C.M. Hwang, J.D. Pan, R.W. Balluffi : J. Appl. Phys. Vol. 50 (1979), p. 1339 doi:10.1063/1.326168

[9] I. Kaur, Yu Mishin and Gust, Fundamentals of Grain and Interphase Boundary Diffusion, Third enlarged edition, John Wiley \& Sons Ltd (1995)

[10 ] J.C.M. Hwang, J.D. Pan, R.W. Balluffi: J. Appl. Phys. Vol. 50 (1979), p. 1335

[11 ] G. Martin: Phys. Rev. B Vol. 41 (1990), p. 2279 doi:10.1103/PhysRevB.41.2279

[12 ] Z. Erdélyi, D.L. Beke: Phys. Rev. B Vol. 70 (2004), p. 245428 doi:10.1103/PhysRevB.70.245428 
[13 ] D.L. Beke, C. Cserháti, Z. Erdélyi, I.A. Szabó: "Segregation in Nanostructures", in Nalwa, H.S. (Ed.), Advances in Nanophase Materials and Nanotechnology: Vol. Nanoclusters and Nanocrystals, American Scientific Publisher, Stevenson Ranch, California (2002)

[14 ] Z. Erdélyi, G.L. Katona, D.L. Beke: Phys. Rev. B Vol. 69 (2004), p. 113407 doi:10.1103/PhysRevB.69.113407

[15 ] Z. Erdélyi, I.A. Szabó, D.L. Beke: Phys. Rev. Lett. Vol. 89 (2002), p. 165901

[16 ] Z. Erdélyi, M. Sladecek, L.-M. Stadler, I. Zizak, G.A. Langer, M. Kis-Varga, D.L. Beke, B. Sepiol: Science Vol. 306 (2004), p. 1913

doi:10.1126/science. 1104400

PMid:15591196

[17 ] A. Csik, G.A. Langer, D.L. Beke, Z. Erdélyi, M. Menyhárd, A. Suloyk: J. Appl. Phys. Vol. 89 (2001), p. 804 doi:10.1063/1.1331330

[18 ] D.L. Beke, Z. Erdélyi: Phys. Rev. B Vol. 73 (2006), p. 035426 doi:10.1103/PhysRevB.73.035426

[19 ] B. E. Deal, A. Groves: J. Appl. Phys. Vol.36 (1965), p.3770 doi:10.1063/1.1713945

[20 ] F. Nemouchi, D. Mangelick, C. Bergmann, P. Gas, U. Smith: Appl. Phys. Lett. Vol.86 (2005), p.041903 doi:10.1063/1.1852727

[21 ] D.L. Beke, Z. Erdélyi, Z. Balogh, Cs. Cserháti, G.L. Katona: proceedings of Diffusion in Solids and Liquides 2008 (DSL-2008) conference (in print)

[22 ] Z. Erdélyi, D.L. Beke, A. Taranovskyy: Appl. Phys. Lett. Vol. 92 (2008), p. 133110 doi:10.1063/1.2905334

[23 ] C. Cserháti, Z. Balogh, A. Csik, G.A. Langer, Z. Erdélyi, GY. Glodán, G.L. Katona, D.L. Beke, I. Zizak, N. Darowski, E. Dudzik, R. Feyerherm: J. Appl. Phys. Vol. 104 (2008), p. 024311 doi:10.1063/1.2957071

[24 ] J. Bernardini, Zs. Tôkei, D.L. Beke, Phil. Mag. A Vol. 73 (1996), 237 doi:10.1080/01418619608242980

[25 ] Z. Balogh et al. (this volume) 
[26 ] H. Mehrer, Landolt-B"ornstein, New Series (Berlin: Springer-Verlag, 1990), chap. 12.

[27 ] C. Cserháti et al. (this volume) 